Article

\title{
Developing a GIS-Based Visual-Acoustic 3D Simulation for Wind Farm Assessment
}

\author{
Madeleine Manyoky ${ }^{1}{ }^{*}$, Ulrike Wissen Hayek ${ }^{1}$, Kurt Heutschi ${ }^{2}$, Reto Pieren ${ }^{2}$ \\ and Adrienne Grêt-Regamey ${ }^{1}$
}

1 Planning of Landscape and Urban Systems, Swiss Federal Institute of Technology Zurich, Zurich CH-8093, Switzerland; E-Mails: wissen@nsl.ethz.ch (U.W.H.); gret@nsl.ethz.ch (A.G.-R.)

2 Empa, Swiss Federal Laboratories for Materials Science and Technology, Duebendorf CH-8600, Switzerland; E-Mails: kurt.heutschi@empa.ch (K.H.); reto.pieren@empa.ch (R.P.)

* Author to whom correspondence should be addressed; E-Mail: manyoky@nsl.ethz.ch; Tel.: +41-44-633-6246; Fax: +41-44-633-1084.

Received: 24 November 2013; in revised form: 20 December 2013 / Accepted: 7 January 2014 / Published: 17 January 2014

\begin{abstract}
Public landscape impact assessment of renewable energy installations is crucial for their acceptance. Thus, a sound assessment basis is crucial in the implementation process. For valuing landscape perception, the visual sense is the dominant human sensory component. However, the visual sense provides only partial information about our environment. Especially when it comes to wind farm assessments, noise produced by the rotating turbine blades is another major impact factor. Therefore, an integrated visual and acoustic assessment of wind farm projects is needed to allow lay people to perceive their impact adequately. This paper presents an approach of linking spatially referenced auralizations to a GIS-based virtual 3D landscape model. We demonstrate how to utilize a game engine for 3D visualization of wind parks, using geodata as a modeling basis. In particular, the controlling and recording of specific parameters in the game engine is shown in order to establish a link to the acoustical model. The resulting prototype has high potential to complement conventional tools for an improved public impact assessment of wind farms.
\end{abstract}

Keywords: wind farm planning; wind turbine noise; landscape impact assessment; GIS-based 3D visualization; game engine; auralization; visual-acoustic simulation 


\section{Introduction}

Planning of new renewable energy installations in the landscape is a complicated matter in Switzerland and all over Europe. Although the public generally supports the renewable energy deployment, the implementation of new installations often fails when it comes to choosing appropriate locations, especially regarding wind farm locations on the local level [1,2]. Cowell [3] points out the "split between the technical and the social" as a key problem: the technical potential is taken as basis for national wind power targets in a top-down approach (e.g., [4]), lacking the public's judgment about the acceptability in particular places. According to recent studies, however, social acceptance is a key issue for successful wind energy market development [5,6]. Furthermore, stakeholders state that there are no suitable instruments to support social acceptance [7].

The impact of the new infrastructures on a specific type of landscape characterized by aesthetical quality and a sense of place is one of the most significant factors explaining support or rejection of wind farms [1,2]. Although the visual sense is the dominant human sensory component for landscape perception, it only provides partial information about our environment [8]. Therefore, a multi-sensory approach for landscape assessment is needed. With regard to wind parks people perceive the noise generated by rotating turbine blades as one of the most prominent annoyance factors $[9,10]$, which is linked to the visual attitude of the wind turbines in the landscape [11]. Hence, there is a strong need for integrating this factor of landscape quality into the site planning of wind farms in order to allow the identification of socially accepted locations for wind power technologies.

\subsection{Technological Advances in Digital Landscape Visualizations}

In the last few decades, the technological advances in digital landscape visualization tools and techniques allow landscape and urban planners to use digital 3D visualizations as a common feature for landscape design, planning and management [8]. Highly detailed 3D vegetation for landscape visualizations (e.g., Laubwerk plants [12], XfrogPlants [13] or the SpeedTree Toolkit [14]), integrated augmented reality and Geographic Information System (GIS) representations [15], multi-player capabilities, and communication possibilities [16-18] are just a few examples. These advances hold great potential for landscape planners in a diversity of applications such as participatory purposes, communication, scenario evaluation, and the decision-making process [19]. GIS-based 3D visualizations have proved to facilitate the communication between various stakeholders, professionals, and the public in the context of participatory wind power development [20,21]. In the landscape planning context, currently emerging game engines offer interesting modeling tools providing state-of-the-art visualizations [22]. Game engines are software programs including different modules for 2D and 3D representations, and generic physics calculations [23] to design computer games. These engines allow for a high level of interactivity and support multiplayer capabilities with online communications [19]. Some of them are available for low prices in the case of non-commercial use and are designed to run on low budget computers as well $[22,24]$. One major advantage of game engines is the ability to create real-time visualizations, which do not require a time consuming rendering step, where each camera position and physical parameter has to be set before the visualization can be presented. Instead, real-time visualizations allow the user to move freely through the environment and to dynamically 
alter physical parameters in the virtual landscape, such as daytime settings or the weather conditions. The ability of game engines to create virtual landscapes with controllable and changeable real world parameters can lead to a suitable planning tool to support communication in decision-making processes. Bishop [19] states that realistic gaming tools configured as a collaborative virtual environment can help people to explore complex issues, run scenario models, and develop acceptable plans. Furthermore, the user's understanding of the real world can be supported by the interactivity and dynamics of virtual environments [25]. If these gaming tools include crucial physical forces and processes of the landscape and also support multi-user capabilities, it would be a logical extension to present such game environments to communities in order to further the design of sustainable future landscapes [19].

\subsection{Game Engines for Landscape Visualizations}

Using a game engine for landscape visualization and planning, Stock et al. [18] showed how Torque's Game Engine [26] can be employed to establish a web-based map server to create a collaborative environment. Jacobson and Lewis [27] presented an immersive cave-like virtual reality projection of landscapes using the Unreal Engine [28]. Nakevska et al. [29] illustrate examples of a cave-environment using Crytek's CryENGINE [30] interfacing the game engine with sensors and input devices for interacting with the virtual environment. Friese et al. [22] analyzed the visualization and interaction capabilities of different game engines, and decided to use the CryENGINE for modeling landscape visualizations because large outdoor terrains can be generated and edited interactively. The CryENGINE was used by Germanchis et al. [31,32] as well, because the CryENGINE was the most stable, easiest to learn and most powerful engine to generate a virtual environment.

A major advantage of the CryENGINE 3 is that it incorporates a physics engine, which can be applied to almost all objects within the virtual world and allows realistic interaction of objects with physical forces such as wind, gravity, friction, and collisions [30]. Therefore, the engine does not rely on precomputed effects but is capable of displaying physically-based phenomena such as dynamic daytime simulation in real-time, changes in vegetation and cloud movement due to altered wind speed [33].

\subsection{Game Engines and Geodata}

Germanchis et al. [31,32] uses a workflow to integrate geodata into the game engine transforming the data into an appropriate form for the game environment to understand. The workflow consists of different stand-alone software programs, e.g., ArcGIS or Photoshop. Herrlich [34] developed a tool to convert real GIS-data into a suitable source readable for the CryENGINE. In the conversion process, Gauss-Krueger coordinates are mapped to game level coordinates. Later, Herrlich et al. [35] show that a game console can be used as a device for geodata visualization and GIS applications, and suggest a way of integrating the standards CityGML and COLLADA for high-quality visualization. However, Friese et al. [22] state that one of the major difficulties encountered during their project using geodata with a game engine were the data conversion processes, as the resolution of the geodata is usually very different compared to the internal engine height map resolution. Furthermore, the coordinate systems of the geodata compared to the internal game engine system vary as well. To get acquainted to the 
import of terrain, 3D objects and other external data from GIS software, time-intensive trials are often necessary [24].

\subsection{Reproduction of Wind Turbine Noise}

With regard to acoustics, the wind turbine noise has to be reproduced for planning future wind farms. Therefore, the audio signals that are suggestive of realistic noise in a given situation have to be synthesized. Sound emission from wind turbines is composed of a mechanical and an aerodynamic component. The mechanical noise is produced by the gearbox and other moving parts of the turbine. The aerodynamic noise on the other hand is generated by air passing the rotor blades. Investigations with microphone arrays have shown that the trailing edge delivers the main contribution to the overall noise [36]. This aerodynamic noise is very broadband with a drop-off towards higher frequencies and can be predicted by numerical calculation methods [37-39].

Overall, sophisticated software tools are provided for either landscape visualization or auralization. However, spatially explicit noise emissions of wind turbines integrated in 3D landscape visualizations providing realistic, accurate, and evaluable representations of the real-world environments are not yet available [40]. This paper describes the development of a visual-acoustic simulation integrating realistic acoustic emission and propagation into GIS-based 3D landscape visualizations to support landscape impact assessments. The visual simulation is generated employing a game engine. For the generation of synthetic wind turbine and environmental noise, the implementation of an emission synthesizer and a propagation filter as well as a reproduction system is developed. The visual and the acoustic simulations are then connected on the basis of linking parameters. These parameters can be controlled via the visual simulation and are transferred to the acoustic simulation to correctly auralize the corresponding soundscape. The focus of this article is the documentation of methods applied for developing the visual-acoustic simulation prototype.

\section{Methods}

First, videos and sound recordings of a case study area had to be produced (Section 2.1). These recordings served as reference for the simulation of the landscape scenery including wind turbines as well as for the acoustic ambience of the wind turbine sound. Then, with regard to the visual simulation (Section 2.2) the essential processes are described: the coordinate transformation to import geodata, the calculation of the wind speed profile, and the visual optimizations to achieve an appropriate level of realism in the visualization. In the acoustic simulation (Section 2.3), the general simulation method and the developed calculation software are briefly described. Finally, Section 2.4 shows how both simulations are linked together.

\subsection{Reference Video and Sound}

The Mont Crosin in the Canton of Berne (Switzerland) was chosen as the reference site for the development of the visual-acoustic simulation tool. The wind farm comprises 16 wind turbines of the type Vestas [41]. On 11 October 2011 and 2 December 2011 the reference recordings were performed at Mont Crosin: video and sound recordings were produced as medium for comparison in order to 
develop the acoustic and visual simulation, and to test the validity of the integrated visual and acoustic simulation tool in a further step.

Prior to fieldwork, reference points at Mont Crosin were defined where videos and acoustic recordings were made, suitable to serve as reference data for both the acoustic and the visual simulation. Thereby, the fundamental auralization aspects were considered, consisting of emission (close vicinity of a wind turbine), ambiance (close to a forest edge), propagation (up to $500 \mathrm{~m}$ distance to a wind turbine), and multi-source recording (two wind turbines from different directions) [42]. Furthermore, constraints for the choice of viewpoints were given by the pedestrians' behavior, i.e., staying on the roads [43]. The contents of views were a frontal wind turbine, a wind turbine in the background, several wind turbines and no wind turbine. The viewing contents, except the "no wind turbine view", were required for comparing the human perception of the contents of the recordings and the simulations in the validation phase, carrying out a visual and acoustic landscape assessment.

In order to assess the acoustic impact of the wind turbines on the landscape under different wind conditions, a recording day with low wind $(3.4 \mathrm{~m} / \mathrm{s}$ at $10 \mathrm{~m}$ above ground) and one with strong wind $(10.6 \mathrm{~m} / \mathrm{s}$ at $10 \mathrm{~m}$ above ground) were chosen. The wind speed measurements were performed with a 3D ultrasonic anemometer. The main audio recordings were taken with a SPS200 Soundfield microphone, which, as a consequence of the strong wind, had to be mounted close to the ground and equipped with a Rycote Windshield and Windjammer. The visual recording system comprised a single-lens reflex camera with video recording capability. A 10-20 mm lens was used and fixed to $10 \mathrm{~mm}$ to capture a field of view of about 100 degrees. Videos were captured to catch the movement of the wind turbines and the vegetation influenced by the wind conditions on the recording days. The recording position in the field, viewing directions, wind speed, and wind direction parameters were compiled in a storyboard.

In addition, aerial images from the reference site were captured using an unmanned aerial vehicle (UAV). The aerial images were photogrammetrically processed, and a digital elevation model (DEM) as well as an orthophoto with a resolution in the decimeter range was calculated. This geodata can not only be used as an accurate and up-to date basis for landscape visualizations but also for determining the correct wind turbine positions in the landscape. The latter was particularly beneficial because the wind farm was recently enlarged and existing aerial images were outdated.

\subsection{Visual Simulation}

Using the Sandbox-Editor of Crytek's CryENGINE Version 3.3.9 [30], an interactive GIS-based 3D visualization with a high level of realism was generated. To visualize the landscape structure including the hilly terrain of the reference site, the visualization perimeter was set to a size of $8 \times 8 \mathrm{~km}$. Because the UAV data covered only $3 \mathrm{~km}^{2}$ of the reference site of Mont Crosin, we decided to use the UAV data mainly for determining the correct placement of the 3D models. The 3D landscape simulation is therefore based on a DEM and an orthophoto of the Mont Crosin from swisstopo [44]. In addition, 3D models for vegetation, infrastructures, and wind turbines were added according to their actual locations, as shown in Figure 1. 
Figure 1. Visual simulation process of the wind farm at Mont Crosin.

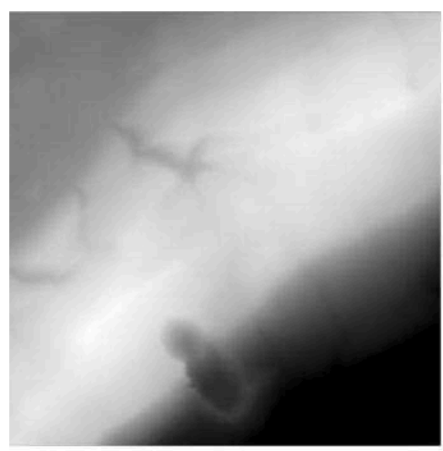

Digital Elevation Model (DEM)

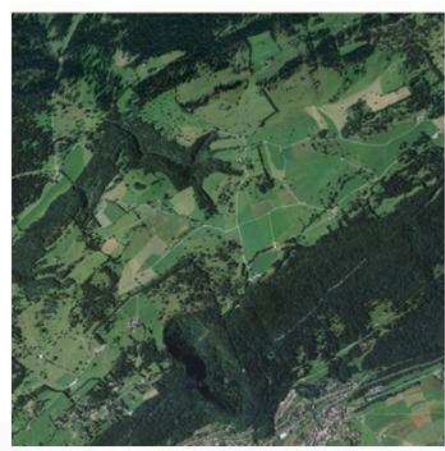

Orthophoto
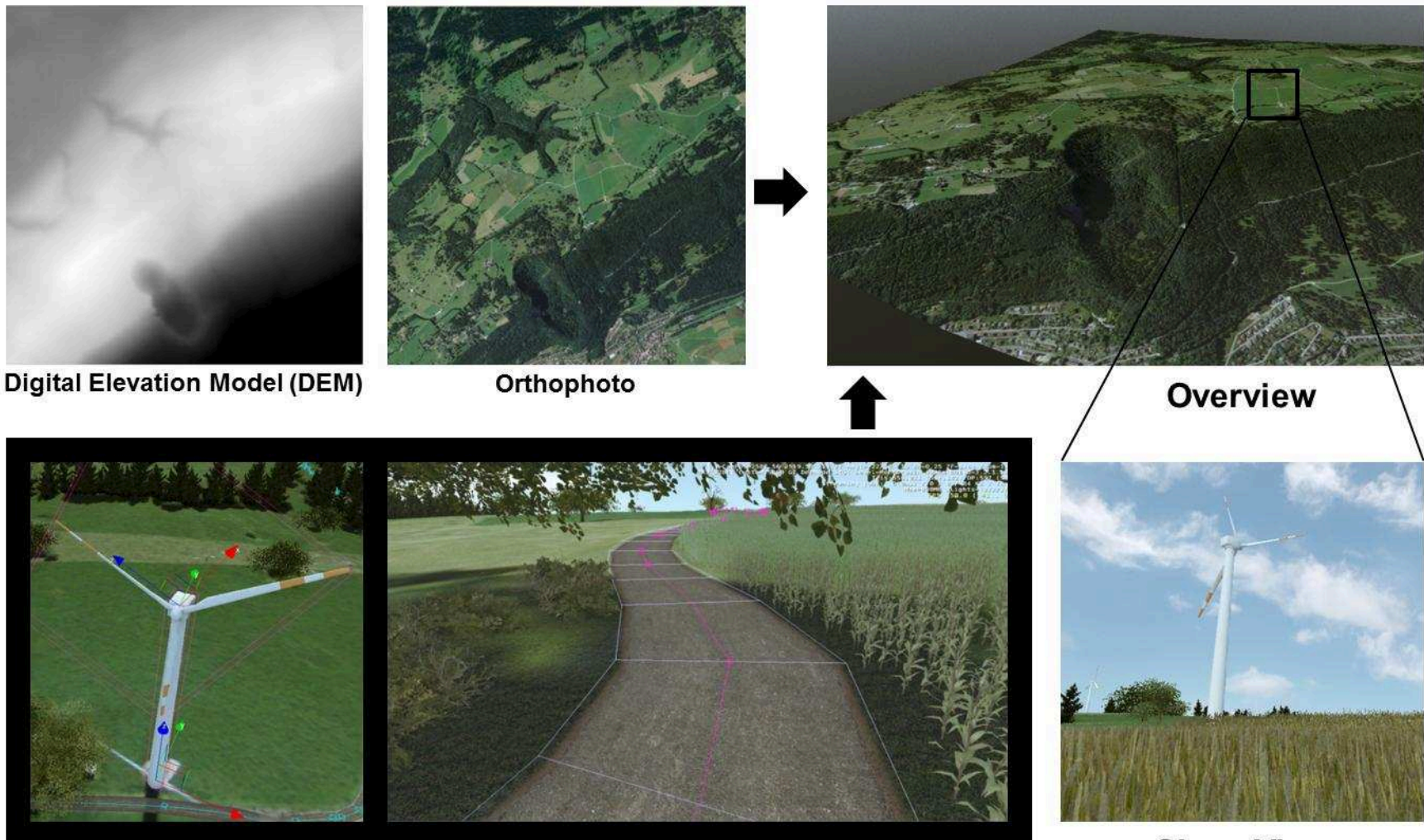

Landscape with additional 3D objects

Overview

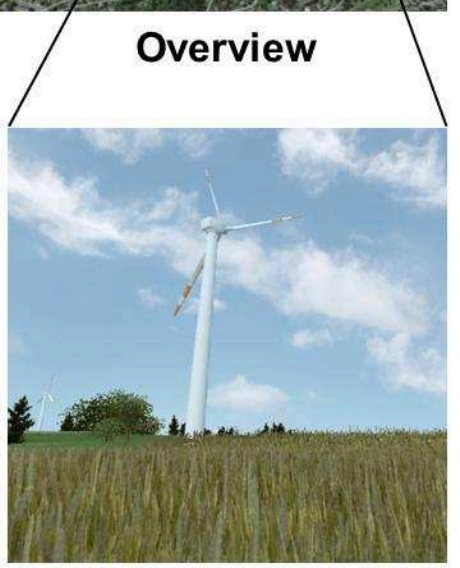

Close View

A major task was to import and reference the geodata accurately because the game engine does not yet provide a direct GIS functionality. Therefore, conversion rules were defined, e.g., to import the digital elevation model so that the heights were displayed correctly in the virtual 3D model.

Figure 2. Digital Elevation Model overlaid with an orthophoto and correctly placed wind turbines.

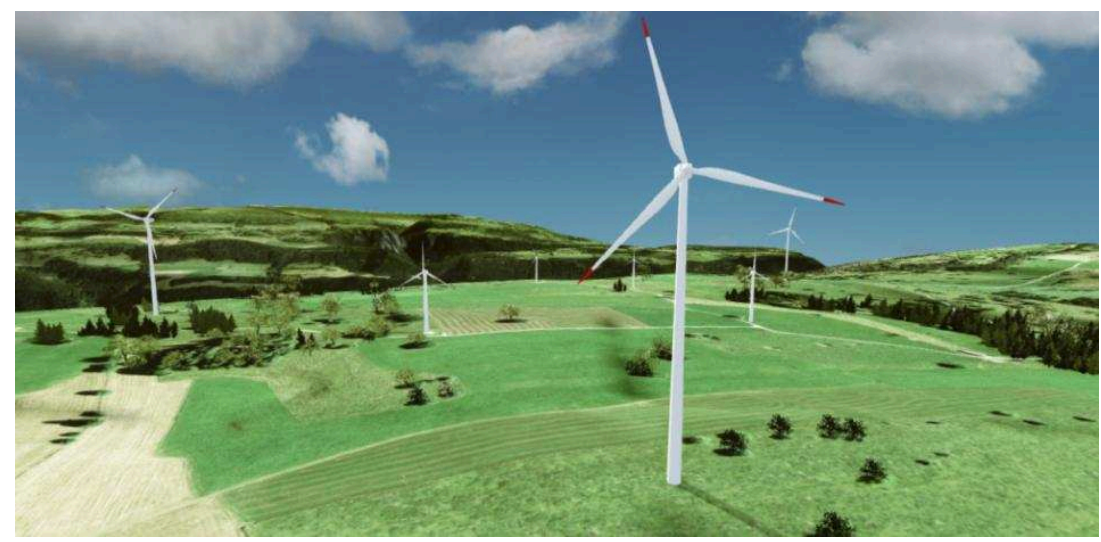

For this task, we took advantage from the CryENGINE's ability to interpret gray values from a height map [45]. Using an 8 bit height map allowing 256 gray values, an area with height differences over $255 \mathrm{~m}$ causes the height resolution to be larger than $1 \mathrm{~m}$. In the reference region of Mont Crosin, the perimeter of $8 \times 8 \mathrm{~km}$ has differences of about $900 \mathrm{~m}$ in height, including a mountain of about 1,000 $\mathrm{m}$ above sea level. Therefore, the height resolution is about $3.5 \mathrm{~m}$ per height unit $(900 \mathrm{~m} / 256=3.53 \mathrm{~m})$. 
Working with 16 bit data files reduces this problem having over 65,000 grey values to represent even small height displacements. Before importing a greyscale terrain, e.g., a GIS-based DEM, the "Maximum Height" value in the engine has to be set. The "Maximum Height" corresponds to the maximum height difference in the perimeter that is the maximal height minus the minimal height of the DEM. The "Maximum Height" value sets the maximum terrain height which the imported terrain can be raised to [33]. Using the terrain editing functions in the engine, the elevation can be smoothed to achieve a better looking base model map [45]. The resulting basic model of the reference site is shown in Figure 2.

\subsubsection{Coordinate Transformation}

The auralization module requires information about the source and receiver position in order to link the respective sound to the view accurately. To get the current user position in the visualization in real world coordinates, transformation parameters have to be set which are applied in real-time to the CryENGINE coordinates. The auralization and the visualization are based on geodata in the Swiss coordinate system (LV03). Because the Swiss coordinate system is a Cartesian system and is defined to have only positive coordinate values within Switzerland, the conversion formula can be simplified to a translation. The translation parameter corresponds to the real world coordinates of the CryENGINE's origin, implicating the shift of the origin coordinates between the perimeter and the CryENGINE. By adding the translation parameters ( $X_{\text {CHofCEorigin }} / Y_{\text {CHofCEorigin }}$ ) to the current position coordinates in CryENGINE $\left(X_{C E \text { Cos }} / Y_{\text {CEpos }}\right)$, the lateral real world position of the user in Swiss coordinates is known at any time:

$$
\begin{gathered}
X_{\text {CHpos }}=X_{\text {CEpos }}+X_{\text {CHofCEorigin }} \\
Y_{\text {CHpos }}=Y_{\text {CEpos }}+Y_{\text {CHofCEorigin }}
\end{gathered}
$$

The height coordinate $Z_{C H \text { pos }}$ is dependent on the minimal height of the visualization perimeter in Swiss coordinates $Z_{C H \text { min }}$ and the height value of the current position in CryENGINE $Z_{C E \text { os }}$. The $Z_{C H \min }$ parameter corresponds to the $0 \mathrm{~m}$ height map value in CryENGINE.

$$
Z_{\text {CHpos }}=Z_{\text {CHmin }}+Z_{\text {CEpos }}
$$

Further deformation or distortion factors of the earth were not taken into account because of the small size of the perimeter, where these factors are negligible.

\subsubsection{Wind Speed Profile}

The movement of the vegetation and the rotational speed of the turbine blades depend on wind direction and speed. Therefore, an algorithm was developed to adjust the wind speed and direction by user interaction (e.g., key inputs) affecting the movement of the vegetation and the wind turbine blades in the virtual model. This algorithm assumes a wind speed profile to calculate the wind speed at hub height. The wind field is determined by pressure differences in the atmosphere. Near the ground surface the wind speed is lower due to friction losses. In addition, the vertical wind speed profile depends on atmospheric stability caused by the temperature layers influencing the vertical movement of the air particles. The wind speed profile is calculated as follows [46-48]: 


$$
w_{z}=w_{10 m}\left(\frac{z}{10 m}\right)^{m}
$$

To calculate the wind speed $\left(w_{z}\right)$ at a specific height $(z)$, the wind speed $10 \mathrm{~m}$ above ground $\left(w_{10 \mathrm{~m}}\right)$ and an atmospheric exponent $(\mathrm{m})$ is needed. In this project, the wind speed $10 \mathrm{~m}$ above ground is defined as the global and adjustable wind speed parameter in CryENGINE influencing the vegetation movement. The wind speed at hub height is then calculated with Equation (3). The m-exponent is dependent on the atmospheric stability class. This is calculated based on the current solar radiation, respectively, the cloud cover at day or night time. In the visualization, this can be defined and changed interactively influencing the wind profile and therefore the theoretical wind speed at hub height.

The wind profile was scripted within the simulation using the visual scripting system "Flow Graph", which is embedded in the CryENGINE Sandbox editor [45]. The "Flow Graph" provides a library of functions and represents them and their connections visually to easily generate and control logical processes. Figure 3 shows an excerpt of the implemented formula Equation (3) in the "Flow Graph" script. As the wind turbine Vestas V90-2MW changes the rotational speed for different wind speed thresholds, rotation modes (M0-M3) were established in field (see Section 2.3). The wind speed at hub height indicates the rotation mode in which the wind turbine is currently operating. The output of Equation (3) (in the "Math:Mul"-Box in the middle of Figure 3) is directed to the wind turbine rotation modes (M0-M3), where the corresponding mode value regulates the speed function of the wind turbine rotor blades. In reality, the wind turbines never move synchronously. To run the wind turbines asynchronously in the simulation, a random value is added to the rotation speed and to the initial position of the rotor blades.

Figure 3. Section of the "Flow Graph" script developed in CryENGINE to control the specific parameters for wind speed profile calculation and corresponding wind turbine rotation in the virtual landscape model.

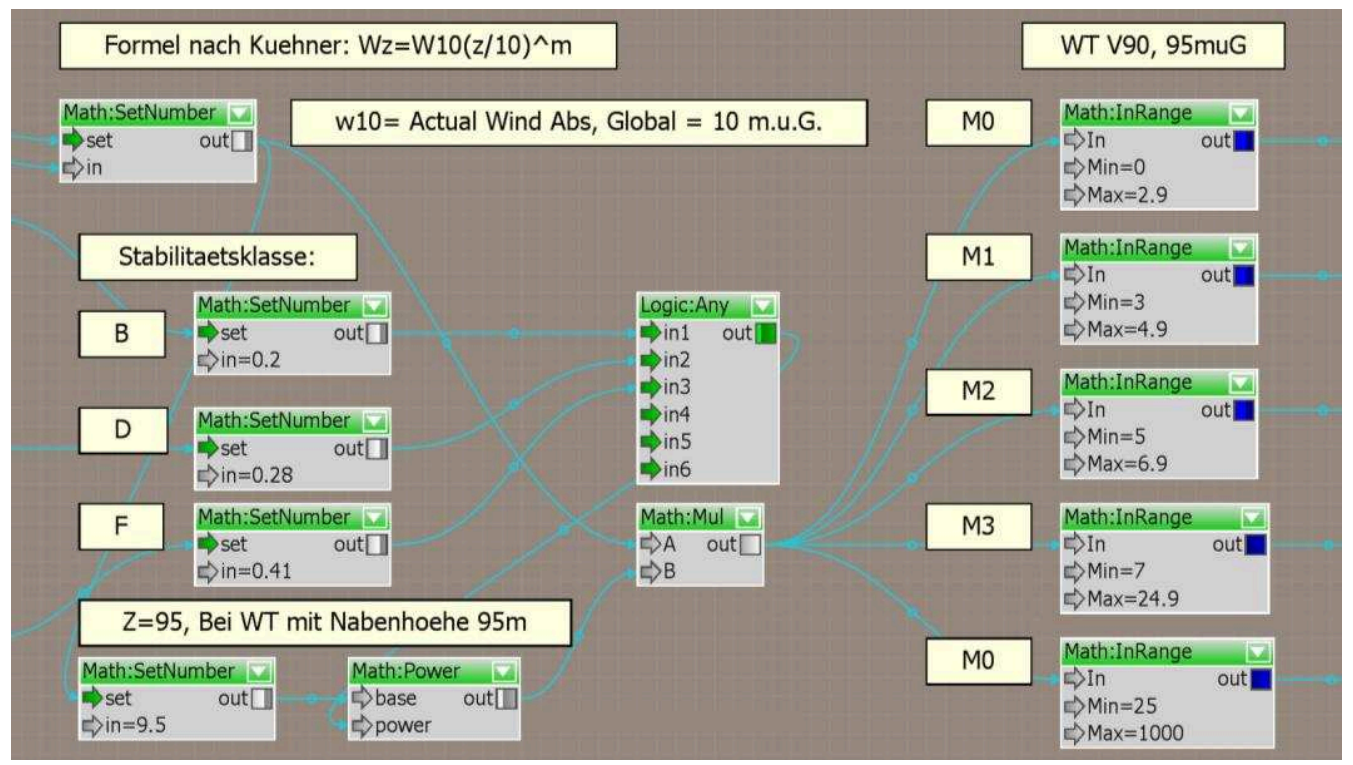

The script allows the user to control the wind speed and direction, allowing changing the wind turbine rotation in the engine in real-time while walking in the virtual 3D model. 


\subsubsection{Visual Optimizations}

Landscape elements of 3D visualizations such as terrain, vegetation and built forms can have different levels of abstraction [49]. Each element has a geometric depiction (e.g., a polygon) with an association of textural properties on the geometric surface [49,50]. For their representation, Danahy [49], Lange [51] and Wissen [50] describe different scales in respect to their level of abstraction, ranging from abstract to realistic representations. Lange [51] states that from a modeling point-of-view, a visualization is more realistic, the more specific textures and geometries are used for modeling represented objects. Furthermore, a higher level of realism can be acquired by integrating and adjusting atmospheric conditions such as weather conditions, natural illumination or the simulation of dynamic processes [52-54]. In this project, we tried to visualize the reference locations in a high but appropriate level of realism. An appropriate level of realism should allow inducing perceptions of the simulated landscape similar to the reference recordings. To achieve this, the following visual optimizations were applied.

The reference videos were analyzed with regard to the wind turbine orientation and rotation, the lighting and weather conditions, and the vegetation movement as well as the structure of the vegetation in the landscape (type, height, density and distribution). The vegetation was animated according to the measured wind speed in field and the movement in the reference video, and with the additional help of the aerial images the vegetation was placed accurately in the visualization.

The lighting conditions were adjusted using the CryENGINE's ability to simulate different daytimes. Based on the reference data collected in field, the daytime and the weather conditions, such as cloud cover, wind speed, wind direction, sun intensity, and sun settings were set in the game engine. The sun settings allow adjusting the position of the sun, the sun direction (the direction from where the sun rises), and the daytime. The sun position implies the distance the perimeter is located from the North Pole to the South Pole, and can be estimated using the real latitude position of the perimeter (for the reference site: $48^{\circ} \mathrm{N}$ in WGS84). As the CryENGINE sun position values range from 0 (=North Pole) to 180 (=South Pole) [33], the sun position value in the sun settings is 42 for the reference site.

Furthermore, the orthophoto color was adjusted to match with the current ground color in the reference videos, using an image editing application. This was necessary for the strong wind situation because the orthophoto was captured at a slightly different season and weather condition than the reference videos.

For the strong wind condition, the sky was covered with fast moving clouds. As these moving clouds are giving an impression of a typical windy environment, this effect has to be implemented as well in the visual simulation, using CryENGINE's 3D clouds [33]. Corresponding to the cloud moving direction in the reference video, the moving path for the major clouds was defined in the visual simulation, leading to an appropriate visual windy effect in the landscape visualization.

For the low wind situation, direct sun exposure was present on the recording day, generating fast moving shadows on the ground from the wind turbine rotors as well as smaller, stationary shadows from the vegetation. Due to the dynamic shadow calculation of the CryENGINE the shadows could be reconstructed accurately with respect to the reference recordings. 
The available 3D wind turbine object models obtained from the software library of WindPRO [55] were resized in the software 3D Studio Max from Autodesk [56] corresponding to the wind turbine sizes on the reference site, including the wind turbines' heights, mast diameters, and the rotor blade dimensions. Additionally, the wind turbine color material was adjusted in order to match the appearances and visual attributes of the real ones. To obtain a 3D wind turbine object file, readable in CryENGINE (e.g., .cgf, .mtl and .dds), the exporter of the CryENGINE 3ds Max Plugin [57] was used. The wind turbine rotor and the mast were imported as separate objects to animate the rotor independently from the mast. In the CryENGINE's "Flow Graph", the rotor is linked to a rotation function, which specifies the movement of the rotation direction $(x, y, z)$ and the rotational speed. Linking the wind turbine rotor to the mast using CryENGINE's "Link Object" function, it is possible to change the entire wind turbine orientation based on the wind direction, while all wind turbine rotors can be steered individually with respect to the wind speed.

All these visual adjustments led to an appropriate landscape visualization providing a level of realism suitable for a visual perception evaluation of the simulated landscapes in the validation part of the project [40].

\subsection{Acoustic Simulation}

The acoustic simulation consists of the generation of the wind turbine emission audio signal (1), the filtering to account for the frequency dependent sound propagation attenuation (2), the generation of a natural background audio signal (3), and the reproduction by loudspeakers (4) as shown in the block diagram in Figure 4.

Figure 4. Block diagram for the generation of synthetic wind turbine and environmental noise.

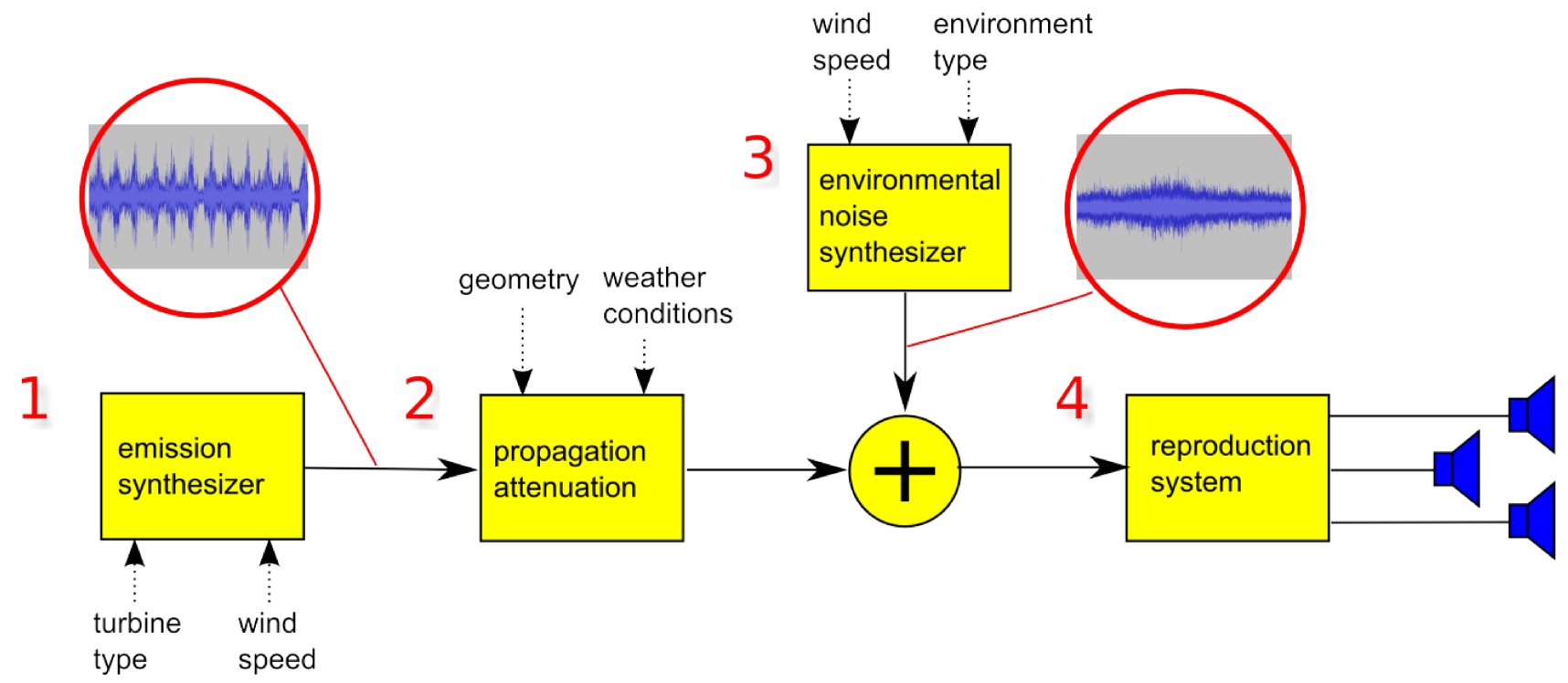

In a first step, the emission synthesizer (1) was developed to generate the emission audio signal. A key issue was the investigation of the emission signal dependency from turbine type and operation condition, wind speed, and temperature stratification. Hence, in addition to the field survey for the reference video and sound from October to December 2011 (see Section 2.1) several emission recordings of wind turbines at varying operation conditions were taken at the reference site at Mont 
Crosin. Instead of an expected continuous relation between wind speed and rotational speed, the measurements on Vestas V90-2MW turbines revealed discrete operational modes (M0-M3). A synthesis model for the generation of emission audio signals of the Vestas V90-2MW was developed and implemented in the software Matlab [58].

In a second step, the frequency dependent sound propagation attenuation (2) was calculated and implemented as a series of digital filters. For that purpose, the computer program AuraPRO in Figure 5a was developed [38]. As input, AuraPRO needs information about the linking parameters from the visual simulation (see Section 2.4), such as the coordinates of the source and receiver positions, the weather conditions, and the emission audio file, to be processed. The topography information is obtained from the digital elevation model, which was also the basis for the visual simulation (see Figure 1). Additional objects such as buildings can be defined in a separate text file. The audio wave file containing the emission signal is read and processed to an output wave file. The output represents the sound pressure time function at the receiver position. So far, the propagation includes geometrical spreading, air absorption, attenuation by obstacles, attenuation by foliage (all according to ISO 9613), and ground effects.

Figure 5. Graphical user interfaces of the computer programs (a) AuraPRO and (b) RePRO.

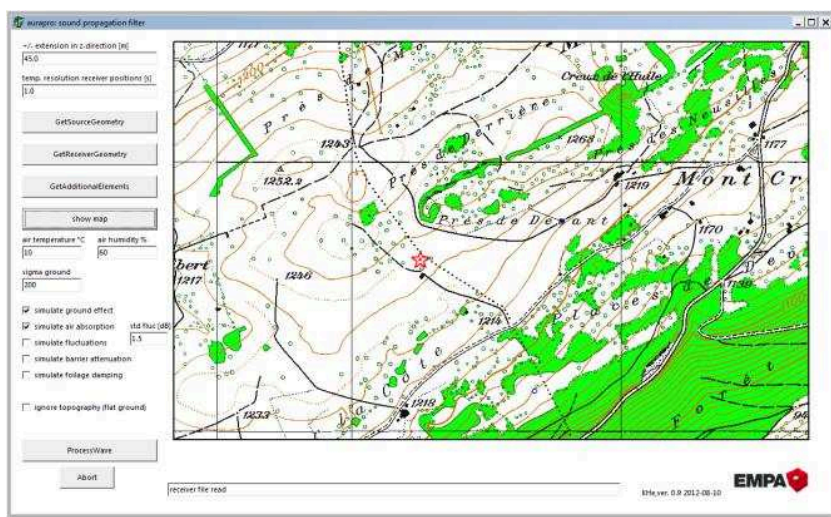

(a)

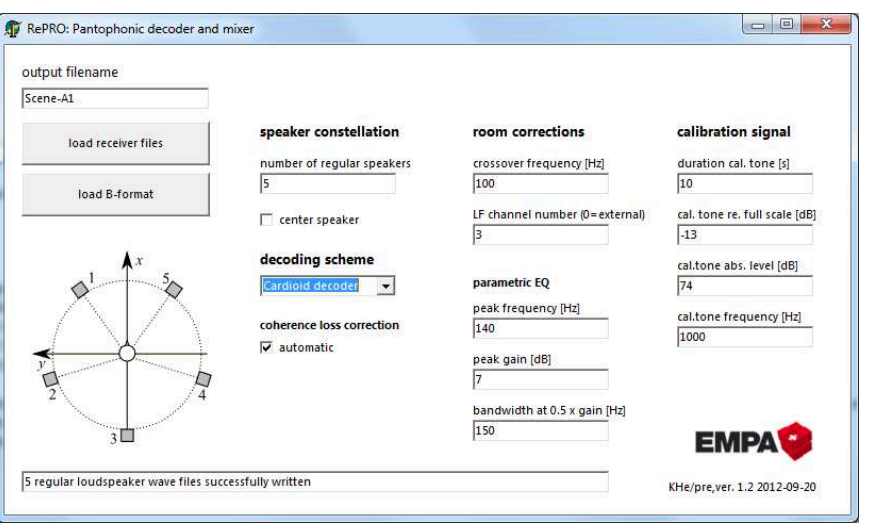

(b)

In a third step, possible vegetation noise is synthesized (3). The model considers the vegetation geometry, the vegetation type, and wind speed [38]. Vegetation noise is modulated in amplitude based on a turbulence model that predicts wind speed fluctuations. As a simplification, these wind speed fluctuations are attributed independently of the individual vegetation cells and not referenced to a location dependent wind speed field.

The sound propagation simulation allows a receiver to change the position over time. Hereby, a procedure had to be developed to map emission samples onto receiver samples for arbitrary time-shifts without audible artifacts. This non-linear operation correctly models the Doppler Effect, that is to say the frequency shift between emitted and received signal in case of a relative movement between source and receiver.

The last step covers a suitable mapping of the synthesized signals to a system of loudspeakers (4) in order to generate an appropriate listening impression regarding sound pressure levels and directional information. In our application, an ambisonics rendering strategy was chosen. Hereby, an arbitrary number of loudspeakers can be used and different coding strategies allow for the optimization of 
system properties such as localization accuracy and extension of the sweet spot. To map the signals to the loudspeaker system, the computer program RePRO was developed, see Figure 5b. Five loudspeakers were arranged in a pentagon-setup to generate an optimal listening impression that allows an appropriate determination of the sound source direction.

\subsection{Linking Acoustic to Visual Simulation}

A concept was developed to connect the acoustic simulation output adequately to the 3D landscape model. As it is not yet possible to generate the acoustic simulation in real-time, the audio files have to be linked to the visualizations in a post-process. This includes three tasks:

1. Rendering images for a video out of the CryENGINE from a viewpoint or a walk path.

2. Saving all relevant parameters which are needed to calculate the audio files (Section 2.3) correctly into a file and providing them to the acoustic simulation calculation.

3. Converting the images into a video, and linking the synthesized audio files to the video using the software Adobe Premiere Pro [59].

Figure 6. Overlaid head-up display (HUD) information of the current position in field and viewing angle (upper left corner) and the current wind speed and direction (bottom left corner).

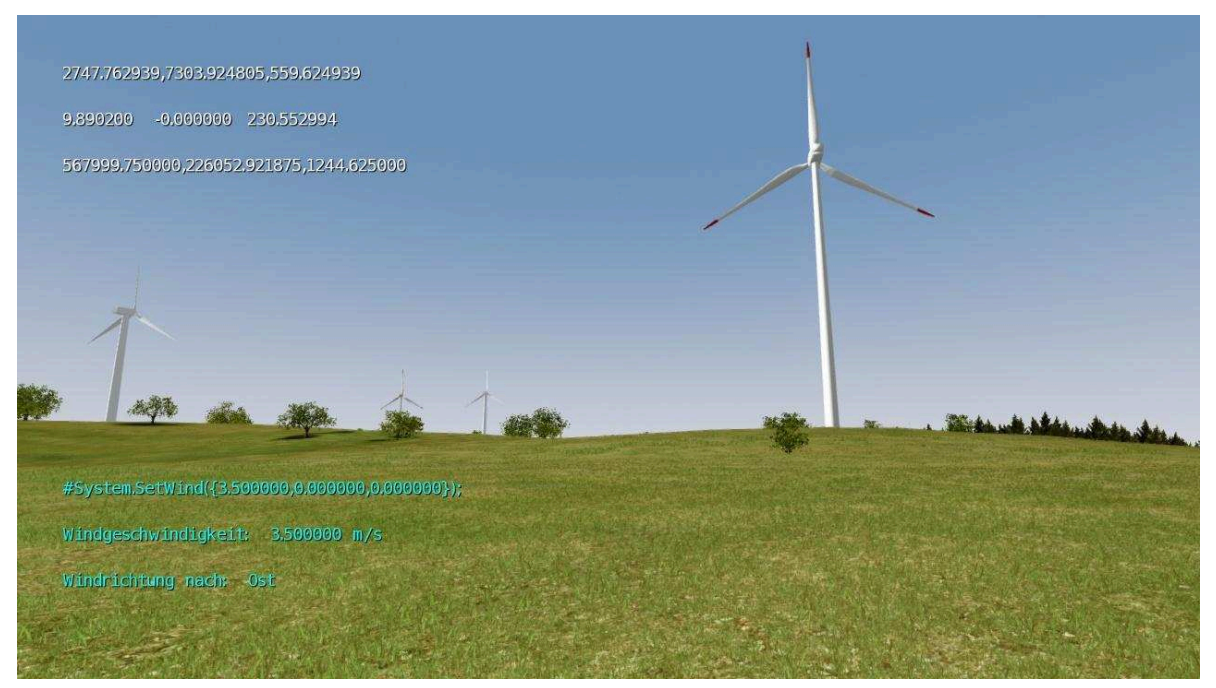

In the first task, images are recorded simultaneously to the movement through the landscape, using a capturing function in the CryENGINE's "Flow Graph" script. In the second task, the parameters relevant for both the acoustic and the visual simulation have to be streamed in real-time into a single parameter file at the same time the images are recorded (step 2). These parameters are: the position, the viewing angle, the wind turbine positions, the turbine rotational speed, the initial rotor position, the wind direction, and the wind speed. Nakevska et al. [29] established an interaction with the game engine generating XML files, where e.g., each object is a child with attributes of the position and the rotation. In our case, the relevant parameters are gathered in the visualization software by the developed "Flow Graph" script (see Section 2.2.2) and streamed into an external XML-file as well. The developed approach allows accessing these parameters in the virtual landscape model and provides the data in a suitable format as input for the auralization model. Based on these parameters, 
the acoustic simulation can be calculated. In the third task, the challenge was to correctly synchronize the movement of the animated wind turbine to the sound files. Therefore, a function was developed in the "Flow Graph" script. First, the actual parameter values are shown in an overlay, the so-called head-up display (HUD) to control the settings of the relevant parameters (see Figure 6).

Then, with a pre-defined key input in the "Flow Graph" script, the HUD parameter information can be hidden and a START sign appears simultaneously for $0.3 \mathrm{~s}$ in the HUD, initiating the rotation of the wind turbines. This START sign indicates the starting time of the simulation and of the parameter file generation. By producing the simulation videos in Adobe Premiere Pro, the corresponding acoustic files can be correctly applied to the visualization based on the visual START information.

\section{Results}

Implementing the presented method, we generated correctly linked visual-acoustic videos of the simulated landscapes. Videos were produced for all the reference locations of Mont Crosin. Figure 7 shows three out of five reference locations, on the left side the reference locations captured in field (see Section 2.1) and on the right side the correspondingly simulated locations.

Figure 7. Three out of five reference (Left) and simulated (Right) landscape videos.

Reference landscapes
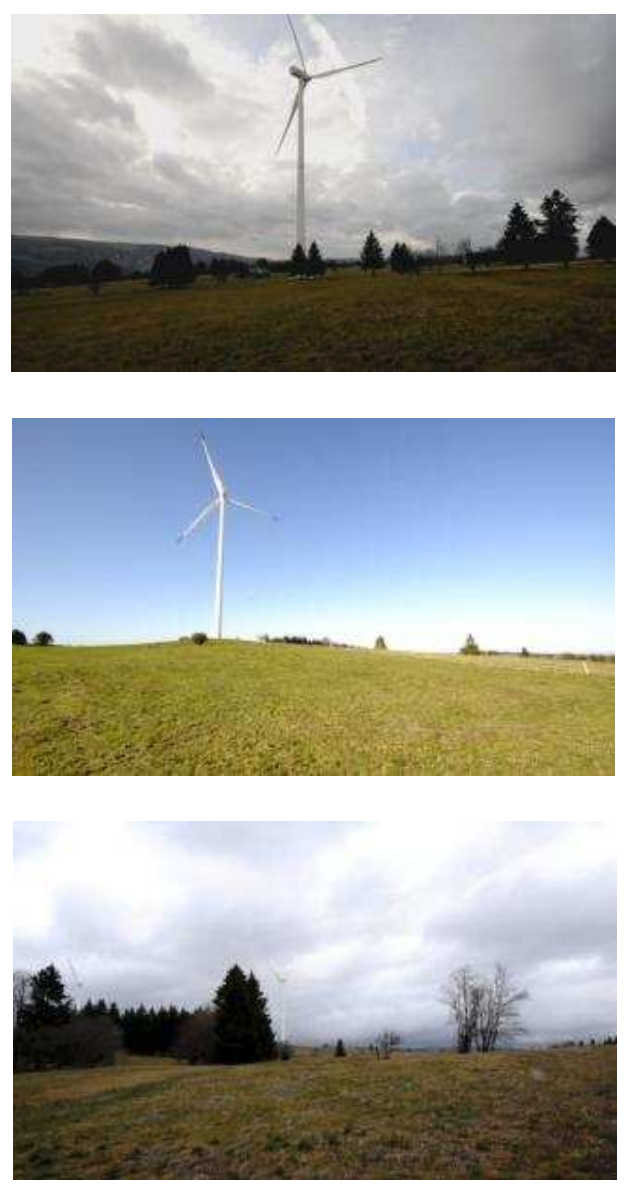

Simulated landscapes
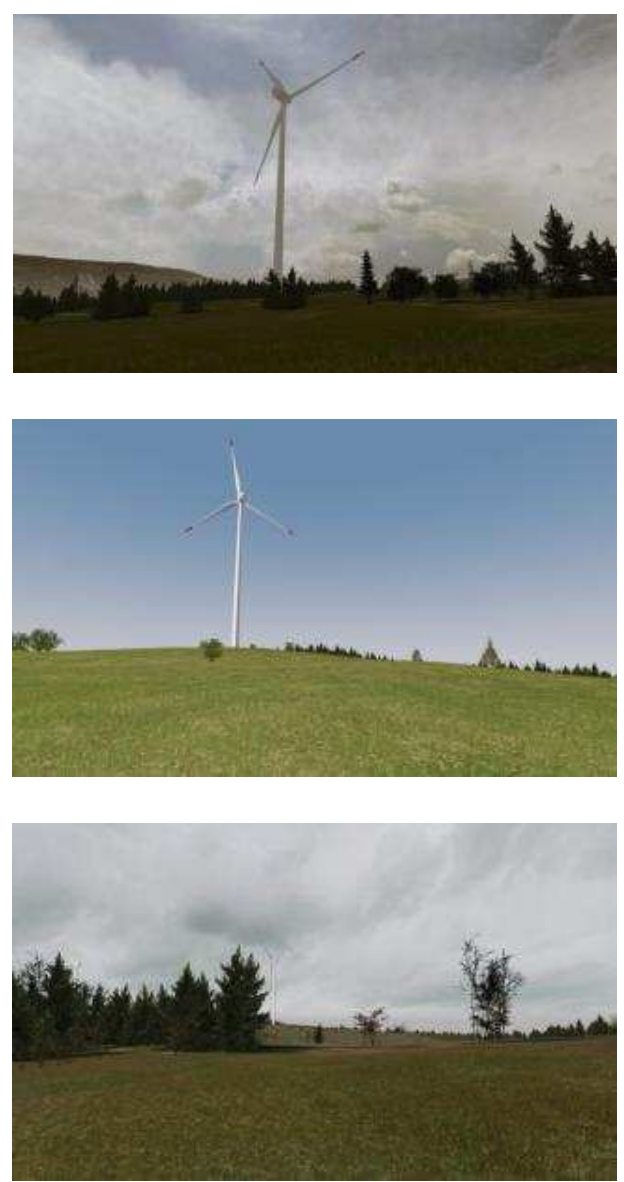


\section{Discussion}

We presented an approach to work with GIS-data in a game engine, to simulate wind turbine noise correctly, and to link the noise simulation to the virtual landscape. This method demonstrates an appropriate way for generating detailed real world landscape representations and for linking the auralization to the virtual landscape.

We produced a GIS-based virtual landscape model employing Crytek's CryENGINE 3. The use of this game engine offered a huge advantage for the visual-acoustic simulation. As Crytek's CryENGINE includes a high performance physics engine, it was possible to create visualizations with great amounts of detail, including vegetation movement, lighting conditions, shadow calculation, and 3D cloud generation. Furthermore, CryENGINE's "Flow Graph" allowed scripting logical processes in an interactive manner, where all relevant parameters for the visual and acoustic simulations can be modified by user interaction and exported in real-time. These features allow linking the visual and acoustic simulation in an appropriate way.

However, since the visualization software is not connected directly to a geographical information system (GIS), it was a major task to integrate and to represent the spatial data accurately and coherently in the game engine. An appropriate transformation of a specific real world coordinate system into internal game engine coordinates is, thus, crucial. The documentation of the straightforward translation approach in this article provides guidance for generating fast and simple GIS-based visualizations with CryENGINE. The translation allows not only for importing geodata and real world coordinate based 3D objects, but also for exporting the linking parameters required for the acoustic simulation adequately.

With the help of the developed tool, it is possible to link the acoustics for an arbitrary wind farm design to a GIS-based landscape visualization in the game engine. Linking parameters defined by predefined settings and changed by user interaction in the visual simulation are stored in a parameter file available for calculating the correct auralization. The wind farm design can be changed interactively and subsequently, the sound is calculated accordingly for the new setting. The user can, thus, choose any location in the virtual landscape and the auralization of the wind turbines can be calculated based on the actual parameters of the location.

The innovative aspects of the developed auralization computer programs are the development of new algorithms and strategies for simulating spatially explicit sound of wind turbines taking into account the environmental context. However, the audio synthesizer is not yet able to calculate and reproduce the audio in real-time. Therefore, the sound files have to be calculated offline in a post-processing step according to the parameter file exported from the visualization module. Currently, the audio information is rendered to five loudspeakers arranged in a pentagon, allowing for optimized source localization with sufficient angular resolution in all directions. In a subsequent step, the audio files are manually linked to the animated virtual landscape video. To avoid the manual integration of video and audio, it would be preferable to use batch procedures that automatically perform the combination (muxing) of video and audio. 
From a technical perspective, an important improvement of the prototype would be the development of real-time functionality of the simulation tool. As it is already possible to change and store the actual linking parameters in real-time, investigations have to be made to generate and auralize the acoustics at the same time the user moves individually through the 3D landscape.

As a next step, this prototype of a visual-simulation tool has to be validated. Both Bishop [19] and Lange [8] state that further developments in visualization techniques help people to understand future landscape changes and therefore influence the decision making process, but it has to be considered how landscape simulations are perceived by humans. Therefore, a validation is needed, where a comparative evaluation is conducted, comparing videos of the simulated wind farm to videos of the real wind farm. The validated tool can then be implemented for further assessments of wind farm scenarios, e.g., in participatory workshop settings as Bishop [19] suggests, or in an acceptability study to assess the impact of different wind farm designs in different landscape contexts. In this way, the development of recommendations for wind farm planning and for exploiting socially-accepted wind energy locations can be supported.

\section{Conclusions}

We developed a prototype of a GIS-based visual-acoustic simulation tool suitable for assessing and discussing choices of locations for wind turbines and their impact on perceived landscape quality in participatory processes. The employed game engine Crytek's CryENGINE 3 has delivered a suitable software program, which proved successful for both (1) realistic 3D visualization of animated wind farms with high level of realism based on GIS-data, as well as (2) providing input parameters for linking spatially explicit acoustic simulations to the accurate locations in the virtual model. With the documentation of the method, we contribute to establishing guidance to generate such visual-acoustic simulations. Overall, this prototype can contribute significantly to enhancing the available set of instruments for conscious landscape development with wind farms. The integration of spatial sound simulation into the correlating virtual landscapes can allow for an improved impact assessment and, thus, it may provide a better, more comprehensible decision basis than conventional tools, such as decibel maps or photomontages.

\section{Acknowledgments}

The work presented was carried out in the scope of the interdisciplinary project "VisAsim-Visual-Acoustic Simulation for landscape impact assessment for wind farms" (2011-2014) funded by the Swiss National Science Foundation, Research Grant: CR21I2_135555. We thank Crytek for providing their game engine for free for our research purposes. In addition, we thank the community crydev.net and crysis-hq.com, namely michi.be, silent. and the_grim for providing custom $3 \mathrm{D}$ vegetation assets.

\section{Author Contributions}

Adrienne Grêt-Regamey, Ulrike Wissen Hayek and Kurt Heutschi developed the overall project concept. Ulrike Wissen Hayek is managing the project and is responsible for the coordination of the 
development of the visual-acoustic simulation tool. Madeleine Manyoky is responsible of the development of the visualization part in the project. Madeleine Manyoky elaborated and simulated the reference situations visually and linked them to the simulated acoustics. Kurt Heutschi and Reto Pieren are responsible for the auralization part in the project. Both authors developed the emission synthesizer, the software AuraPRO for acoustically modeling all relevant propagation effects, the environmental noise synthesizer and the software RePRO for mapping the audio signals to a reproduction system. Madeleine Manyoky elaborated together with Reto Pieren the concept for linking the visual and acoustic simulation, relevant for the correct and synchronized visual and acoustic integration. All authors discussed the development and the results of the visual-acoustic simulation tool at all stages. All authors were involved in the writing process according to their project contribution and commented on the manuscript.

\section{Conflicts of Interest}

The authors declare no conflict of interest.

\section{References}

1. Wolsink, M. Wind power implementation: The nature of public attitudes: Equity and fairness instead of “backyard motives”. Renew. Sustain. Energy Rev. 2007, 11, 1188-1207.

2. Devine-Wright, P. Beyond NIMBYism: Towards an integrated framework for understanding public perceptions of wind energy. Wind Energy 2005, 8, 125-139.

3. Cowell, R. Wind power, landscape and strategic, spatial planning-The construction of "acceptable locations" in Wales. Land Use Policy 2010, 27, 222-232.

4. Bundesamt für Energie BFE; Bundesamt für Umwelt, Wald und Landschaft BUWAL; Bundesamt für Raumentwicklung ARE. Konzept Windenergie Schweiz-Grundlagen für die Standortwahl von Windparks; Bundesamt für Energie BFE, Bundesamt für Umwelt, Wald und Landschaft BUWAL, Bundesamt für Raumentwicklung ARE: Bern, Switzerland, 2004.

5. Hall, N.; Ashworth, P.; Devine-Wright, P. Societal acceptance of wind farms: Analysis of four common themes across Australian case studies. Energy Policy 2013, 58, 200-208.

6. Pepermans, Y.; Loots, I. Wind farm struggles in Flanders fields: A sociological perspective. Energy Policy 2013, 59, 321-328.

7. Bundesamt für Energie BFE. Energieforschung. Code of Conduct für Windkraftprojekte, Machbarkeitsstudie - Schlussbericht; Swiss Federal Office for Energy: Bern, Switzerland, 2009.

8. Lange, E. 99 volumes later: We can visualise. Now what? Landsc. Urban Plan. 2011, 100, 403-406.

9. Shepherd, D.; McBride, D.; Welch, D.; Hill, E.; Dirks, K. Evaluating the impact of wind turbine noise on health-related quality of life. Noise Health 2011, 13, 333-339.

10. Mijuk, G. Der Wind dreht. In NZZ am Sonntag; Neue Zürcher Zeitung AG: Zurich, Switzerland, 2010; pp 22-23.

11. Pedersen, E.; Larsman, P. The impact of visual factors on noise annoyance among people living in the vicinity of wind turbines. J. Environ. Psychol. 2008, 28, 379-389. 
12. Laubwerk GmbH. 3D Plants for CG Artists. Available online: http://www.laubwerk.com (accessed on 29 October 2013).

13. Xfrog Inc. 3D Trees and 3D Plants for CG Artists. Available online: http://xfrog.com (accessed on 29 October 2013).

14. IDV Inc. SpeedTree Animated Trees \& Plants Modeling \& Render Software. Available online: http://www.speedtree.com (accessed on 29 October 2013).

15. Ghadirian, P.; Bishop, I.D. Integration of augmented reality and GIS: A new approach to realistic landscape visualisation. Landsc. Urban Plan. 2008, 86, 226-232.

16. Stock, C.; Bishop, I.D. Linking GIS with real-time visualisation for exploration of landscape changes in rural community workshops. Virtual Real. 2006, 9, 260-270.

17. Stock, C.; Bishop, I.D.; Green, R. Exploring landscape changes using an envisioning system in rural community workshops. Landsc. Urban Plan. 2007, 79, 229-239.

18. Stock, C.; Bishop, I.D.; O’Connor, A. Generating Virtual Environments by Linking Spatial Data Processing with a Gaming Engine. In Trends in Real-time Landscape Visualization and Participation; Buhmann, E., Paar, P., Bishop, I.D., Lange, E., Eds.; Wichmann: Heidelberg, Germany, 2005; pp. 324-329.

19. Bishop, I.D. Landscape planning is not a game: Should it be? Landsc. Urban Plan. 2011, 100, 390-392.

20. Lange, E.; Hehl-Lange, S. Combining a participatory planning approach with a virtual landscape model for the siting of wind turbines. J. Environ. Plan. Manag. 2005, 48, 833-852.

21. Otero, C.; Manchado, C.; Arias, R.; Bruschi, V.M.; Gómez-Jáuregui, V.; Cendrero, A. Wind energy development in Cantabria, Spain. Methodological approach, environmental, technological and social issues. Renew. Energy 2012, 40, 137-149.

22. Friese, K.-I.; Herrlich, M.; Wolter, F.-E. Using Game Engines for Visualization in Scientific Applications. In New Frontiers for Entertainment Computing; Ciancarini, P., Nakatsu, R., Rauterberg, M., Roccetti, M., Eds.; Springer: Boston, MA, USA, 2008; Volume 279, pp. 11-22.

23. Lewis, M.; Jacobson, J. Game engines in scientific research. Commun. ACM 2002, 45, $27-31$.

24. Herwig, A.; Paar, P. Game Engines: Tools for Landscape Visualization and Planning? In Trends in GIS and Virtualization in Environmental Planning and Design; Buhmann, E., Nothelfer, U., Pietsch, M., Eds.; Wichmann: Heidelberg, Germany, 2002; pp. 161-172.

25. Germanchis, T.; Pettit, C.; Cartwright, W. Building a three-dimensional geospatial virtual environment on computer gaming technology. J. Spat. Sci. 2004, 49, 89-95.

26. GarageGames. Game Development Tools and Software. Available online: http://www.garagegames.com (accessed on 29 October 2013).

27. Jacobson, J.; Lewis, M. Game engine virtual reality with CaveUT. Computer 2005, 38, 79-82.

28. Epic Games Inc. Game Engine Technology by Unreal. Available online: http://www.unrealengine.com (accessed on 29 October 2013).

29. Nakevska, M.; Vos, C.; Juarez, A.; Hu, J.; Langereis, G.; Rauterberg, M. Using Game Engines in Mixed Reality Installations. In Entertainment Computing-ICEC 2011; Anacleto, J., Fels, S., Graham, N., Kapralos, B., Saif El-Nasr, M., Stanley, K., Eds.; Springer: Berlin/Heidelberg, Germany, 2011; Volume 6972, pp. 456-459. 
30. Crytek GmbH. MyCryENGINE. Available online: http://mycryengine.com (accessed on 29 October 2013).

31. Germanchis, T.; Cartwright, W.; Pettit, C. Using Computer Gaming Technology to Explore Human Wayfinding and Navigation Abilities within the Built Environment. In Proceedings of the XXII International Cartographic Conference, A Coruña, Spain, 9-16 July 2005; pp. 11-16.

32. Germanchis, T.; Cartwright, W.; Pettit, C. Virtual Queenscliff: A Computer Game Approach for Depicting Geography. In Multimedia Cartography; Cartwright, W., Peterson, M., Gartner, G., Eds.; Springer: Berlin/Heidelberg, Germany, 2007; pp. 359-368.

33. Tracy, D.; Tracy, S. CryENGINE 3 Cookbook: Over 90 Recipes Written by Crytek Developers for Creating Third-Generation Real-Time Games; Packt Publishing Ltd.: Birmingham, UK, 2011.

34. Herrlich, M. A Tool for Landscape Architecture Based on Computer Game Technology. In Proceedings of the 17th International Conference Artificial Reality and Telexistence, Esbjerg, Denmark, 28-30 November 2007; pp. 264-268.

35. Herrlich, M.; Holle, H.; Malaka, R. Integration of CityGML and Collada for High-Quality Geographic Data Visualization on the PC and Xbox 360. In Entertainment Computing-ICEC 2010; Yang, H., Malaka, R., Hoshino, J., Han, J., Eds.; Springer: Berlin/Heidelberg, Germany, 2010; Volume 6243, pp 270-277.

36. Oerlemans, S.; Sijtsma, P.; Méndez López, B. Location and quantification of noise sources on a wind turbine. J. Sound Vib. 2007, 299, 869-883.

37. Schepers, J.G.; Curvers, A.; Oerlemans, S.; Braun, K.; Lutz, T.; Herrig, A.; Wuerz, W.; Mantesanz, A.; Garcillan, L.; Fischer, M.; et al. SIROCCO: Silent Rotors by Acoustic Optimisation. In Proceedings of the 2nd International Meeting on Wind Turbine Noise, Lyon, France, 20-21 September 2007.

38. Heutschi, K.; Pieren, R.; Müller, M.; Manyoky, M.; Wissen Hayek, U.; Eggenschwiler, K. Auralization of wind turbine noise: Propagation filtering and vegetation noise synthesis. Acta Acust. United Acust. 2014, 100, 13-24.

39. Heutschi, K.; Pieren, R. Auralization of Wind Turbines. In Proceedings of the AIA-DAGA 2013 Conference on Acoustics, Merano, Italy, 18-21 March 2013.

40. Manyoky, M.; Hayek, U.W.; Klein, T.M.; Pieren, R.; Heutschi, K.; Grêt-Regamey, A. Concept for Collaborative Design of Wind Farms Facilitated by an Interactive GIS-Based Visual-Acoustic 3D Simulation. In Peer Reviewed Proceedings of Digital Landscape Architecture 2012 at Anhalt University of Applied Sciences; Buhmann, E., Ervin, S., Pietsch, M., Eds.; Wichmann: Heidelberg, Germany, 2012; pp. 297-306.

41. Vestas Wind Systems A/S. Vestas Wind Systems. Available online: http://www.vestas.com (accessed on 29 October 2013).

42. Vorländer, M. Auralization: Fundamentals of Acoustics, Modelling, Simulation, Algorithms and Acoustic Virtual Reality; Springer: Berlin/Heidelberg, Germany, 2008.

43. Braun, S.; Ziegler, S. Windlandschaft: Neue Landschaften mit Windenergieanlagen; Wissenschaftlicher Verlag Berlin (WVB): Berlin, Germany, 2006.

44. Federal Office of Topography Swisstopo. Swisstopo-Knowing Where. Available online: http://www.swisstopo.ch (accessed on 29 October 2013). 
45. Tracy, S.; Reindell, P. CryENGINE 3 Game Development: Beginner's Guide; Packt Publishing Ltd.: Birmingham, UK, 2012.

46. Kühner, D. Excess attenuation due to meteorological influences and ground impedance. Acta Acust. United Acust. 1998, 84, 870-883.

47. Van den Berg, G.P. Do Wind Turbines Produce Significant Low Frequency Sound Levels? In Proceedings of the 11th International Meeting on Low Frequency Noise and Vibration and its Control, Maastricht, The Netherlands, 30 August-1 September 2004; Volume 13, pp. 367-376.

48. Heutschi, K.; Eggenschwiler, K. Lärmermittlung und Massnahmen zur Emissionsbegrenzung bei Windkraftanlagen; Untersuchungsbericht Nr. 452’460, int. 562.2432; Eidg. Materialprüfungs- und Forschungsanstalt, Abteilung Akustik: Dübendorf, Switzerland, 2010.

49. Danahy, J. A Set of Visualization Data Needs in Urban Environmental Planning \& Design for Photogrammetric Data. In Automatic Extraction of Man-Made Objects from Aerial and Space Images (II); Gruen, A., Baltsavias, E., Henricsson, O., Eds.; Birkhäuser: Basel, Switzerland, 1997; pp. 357-366.

50. Wissen, U. Virtuelle Landschaften zur Partizipativen Planung: Optimierung von 3D-Landschaftsvisualisierungen zur Informationsvermittlung; vdf Hochschulverlag AG: Zürich, Switzerland, 2009.

51. Lange, E. Issues and Questions for Research in Communicating with the Public through Visualizations. In Trends in Real-Time Landscape Visualization and Participation; Buhmann, E., Paar, P., Bishop, I.D., Lange, E., Eds.; Wichmann: Heidelberg, Germany, 2005; pp. 16-26.

52. Paar, P.; Schroth, O.; Lange, E.; Wissen, U.; Schmid, W.A. Steckt der Teufel im Detail? Eignung Unterschiedlicher Detailgrade von 3D-Landschaftsvisualisierung für Bürgerbeteiligung und Entscheidungsunterstützung. In Proceedings of the 9th International Conference on Urban Planning and Regional Development in the Information Society, Vienna, Austria, 25-27 February 2004; pp. 535-541.

53. Achleitner, E.; Schmidinger, E.; Voigt, A. Dimensionen Eines Digitalen Stadtmodelles am Beispiel Linz. In Proceedings of the 8th International Conference on Urban Planning and Regional Development in the Information Society, Vienna, Austria, 25 February-1 March 2003; pp. 171-179.

54. Erwin, S.M. Digital landscape modeling and visualization: A research agenda. Landsc. Urban Plan. 2001, 54, 49-62.

55. EMD International A/S. Danish Software and Consultancy Firm Assisting Countries with Planning and Documenting Environmental Energy Projects. Available online: http://www.emd.dk (accessed on 29 October 2013).

56. Autodesk Inc. 3D Design, Engineering \& Entertainment Software. Available online: http://www.autodesk.com (accessed on 29 October 2013).

57. Crytek GmbH. Installing the 3ds Max Tools-Doc 3. Asset Creation Guide. Available online: http://freesdk.crydev.net/display/SDKDOC3/Installing+the+3ds+Max+Tools (accessed on 30 October 2013).

58. Pieren, R.; Heutschi, K.; Müller, M.; Manyoky, M.; Eggenschwiler, K. Auralization of wind turbine noise: Emission synthesis. Acta Acust. united Acust. 2014, 100, 25-33. 
59. Adobe Systems Inc. Adobe Premiere Pro CC. Available online: http://www.adobe.com/ PremierePro (accessed on 29 October 2013).

(C) 2014 by the authors; licensee MDPI, Basel, Switzerland. This article is an open access article distributed under the terms and conditions of the Creative Commons Attribution license (http://creativecommons.org/licenses/by/3.0/). 